\title{
Effects of Incubation Temperature on Egg Development, Hatching and Pigment Plug Evacuation in Farmed Siberian Sturgeon Acipenser baerii
}

\author{
Chulhong Park, Sang Yoon Lee, Dong Soo Kim and Yoon Kwon Nam* \\ Department of Marine Bio-Materials and Aquaculture, Pukyong National University, Busan 608-737, Korea
}

\begin{abstract}
Early ontogenic development in Siberian sturgeon Acipenser baerii was documented and the effects of different temperatures on embryonic and prelarval development were examined. Photograph-assisted data on morphogenesis in Siberian sturgeon prolarvae agreed well with published descriptions of their ontogeny and ecological behaviors, although certain aspects of differentiation, such as gill covering and scute development, could be rearing condition-sensitive. The present study provides the first characterization of the transient development of teeth during early larval stages; the pattern was congruent with the transition of prolarvae to exogenous feeding. From examinations of embryonic and prelarval development under different temperature conditions $\left(12-24^{\circ} \mathrm{C}\right)$, developmental speed was inversely related with temperature. Overall, hatchability was higher and hatching events were more synchronized at $20^{\circ} \mathrm{C}$ than at lower temperatures. After hatching, similar patterns of temperature-dependency were observed in yolk sac absorption and the evacuation of the pigment plug. Our results suggest that the incubation of Siberian sturgeon embryos and prolarvae at temperatures close to $20^{\circ} \mathrm{C}$ would be advantageous in hatcheries, based on reductions in the duration and uniformity of egg and prolarval developmental stages.
\end{abstract}

Key words: Acipenser baerii, Incubation temperatures, Egg development and hatchability, Prolarval development

\section{Introduction}

Sturgeons are one of the most primitive groups of Osteichthyes, and their taxonomic position relative to advanced bony fishes makes them attractive as model systems for studying the evolution and functional diversification of extant fishes (Cho et al., 2007; Kim et al., 2009; Akbarzadeh et al., 2011; Webb and Doroshov, 2011). This group of primitive ray-finned fishes includes various ploidy levels as well as several anatomical features that resemble those of cartilaginous fishes; they also exhibit distinctive morphological characters that are rarely seen in most teleostean fishes (Billard and Lecointre, 2001; Kim et al., 2005; Vasil'ev, 2009). Sturgeon undergo significant and intense morphological differentiations, especially during early life stages, and their morphogenesis during prelarval and larval stages is closely related to their behavioral patterns, such as rheotaxis, phototaxis, and swimming ability (Bolker, 2004; Kirschbaum and Williot, 2011).

Like other cold-blooded animals, environmental temperature is one of the most fundamental and critical factors affecting sturgeon development and physiology. Sturgeon species typically have their own optimum temperature range for proper egg development and larval ontogenesis, and this is one of the critical aspects that needs to be considered in hatchery management (Conte et al., 1988; Birstein et al., 1997; Gisbert and Williot, 2002). Siberian sturgeon Acipenser baerii
Open Access http://dx.doi.org/10.5657/FAS.2013.0025

This is an Open Access article distributed under the terms of the Creative Commons Attribution Non-Commercial License (http://creativecommons, org/licenses/by-nc/3.0/) which permits unrestricted non-commercial use, distribution, and reproduction in any medium, provided the original work is properly cited. pISSN: 2234-1749 eISSN: 2234-1757
Received 12 November 2012; Accepted 23 November 2012

\author{
*Corresponding Author \\ E-mail: yoonknam@pknu.ac.kr
}


is a commercially important, aquaculture-relevant species because of its relatively fast early growth, tolerance for rearing at high densities, and the high quality of its caviar products. This species has become one of the main sturgeon targets in the aquaculture domains of many European countries (Gisbert and Williot, 2002). Siberian sturgeon was introduced to Korea in 1997 as a novel candidate for aquaculture production, and several pioneering works to understand the development, growth characteristics, and reproduction of this sturgeon species have been initiated in Korea (Seong and Baik, 1999; Park, 2012; Park et al., 2013). However, the efficiency of hatching and larval nursery for Siberian sturgeon has remained highly variable among hatcheries in Korea, with the overall yield of larval production ranging from $<10 \%$ to $>80 \%$, depending on the hatchery. This high variation among hatcheries has even been frequently observed within egg batches produced from the same broodfish in one hatchery and then disseminated to other hatcheries. This suggests that the physicochemical parameters in the individual hatcheries that receive egg batches are responsible for the variable yield in larval production. Although the conditions used for egg and larval incubation in each hatchery are affected by a number of biotic and abiotic factors, one parameter that differs notably among Siberian sturgeon hatcheries in Korea is water temperature. A wide range of water temperatures (range, 11 to $19^{\circ} \mathrm{C}$ ) are currently used for larval production, depending on the geographic location and the availability of groundwater for each hatchery (personal communication). Worldwide, temperature conditions during egg and larval development in laboratory experiments, hatchery production, and/or surveys of spawning grounds have varied largely among reports (Gisbert et al., 2000; Gisbert and Ruban, 2003; Zeiske et al., 2003).

However, despite its potential importance, the effects of water temperature on egg development and prelarval differentiation have not been extensively studied in this sturgeon species. As a first step towards improving the capacity and efficiency of hatchery practices for Siberian sturgeon in Korea, we examined the effects of incubation temperature on the development of embryos and prolarvae, up to the transition to exogenous feeding. We also documented early ontogenic development in this sturgeon species to guide our examination of temperature-dependency in prelarval development.

\section{Materials and Methods}

\section{Artificial fertilization and preparation of egg batches}

To examine the effects of temperature on early development, Siberian sturgeon embryos were produced in two different hatcheries. One was from Dinoville Aquafarm Inc., Hamyang-gun, Gyeongsangnam-do, Korea, and the other was from Korea Sturgeon Aquafarm Inc., Miryang City, Gyeong- sangnam-do, Korea. Three egg batches were produced from independent matings in the first hatchery; two egg batches were produced at the second hatchery. For hormonally induced spawning, mature females (8-10 years old) were given intramuscular injections of a luteinizing hormone-releasing hormone analogue (des-Gly ${ }^{10}$, [D-Ala $\left.^{6}\right]$ LH-RH Ethylamide; LHRHa; Syndel Laboratories Ltd., Vancouver, BC, Canada). The dosage was 100-150 $\mu \mathrm{g} / \mathrm{kg}$ body weight (BW), and 10\% was delivered as a primary dose and the remaining $90 \%$ was given as a resolving dose $12 \mathrm{~h}$ after the primary injection. Males were given a single injection of LHRHa, at a dosage of $100 \mu \mathrm{g} / \mathrm{kg} \mathrm{BW}$. Ovulated eggs were artificially inseminated using the wet method, according to previously described procedures (Gisbert and Williot, 2002; Park, 2012).

\section{Documentation of early ontogenic development}

To examine morphological changes in hatchlings, hatched prolarvae were reared in a water recirculating system at $18 \pm$ $0.5^{\circ} \mathrm{C}$. After the evacuation of the pigment plug, larvae were fed with Artemia nauplii (INVE Aquaculture Inc., Salt Lake City, UT, USA) and a powdered artificial diet (50\% crude protein; $200 \mu \mathrm{m}$ in diameter) designed for olive flounder Paralichthys olivaceus larvae (Woosung Feed Corp., Daejeon, Korea) on an ad libitum basis (six times per day). The water exchange rate was $30 \%$ per day and the average dissolved oxygen level throughout larval sampling was $6 \pm 0.5 \mathrm{ppm}$. A random sample of 15-25 fish was obtained every day from just after hatching to 21 days post hatching (dph) to document morphological development and differentiation. Photographs were taken using a digital image analysis system mounted on an AZ100 Stereomicroscope (Nikon Corporation Instruments Company, Tokyo, Japan).

\section{Examination of temperature effects on the devel- opment of embryos and prolarvae}

Three successive experiments were performed to examine the effects of temperature on egg development, hatching, and prolarval development. First, embryonic development in at least 330 fertilized embryos from each egg batch was examined under four temperature treatments $\left(12^{\circ} \mathrm{C}, 16^{\circ} \mathrm{C}, 20^{\circ} \mathrm{C}\right.$, or $24^{\circ} \mathrm{C}$ ). Experimental temperatures were maintained within \pm $0.5^{\circ} \mathrm{C}$ using electric thermostat-assisted temperature controllers. For each temperature group, the time to reach various developmental stages (blastulation, gastrulation, small yolk plug formation, late neurulation, s-heart formation, and the first occurrence of hatching) was monitored. Descriptions of each developmental stage in this species referred to Park et al. (2013). During each of the four selected stages, the survival rate (percentage) was also estimated for each egg batch. Second, the time spectrum of hatching events was examined under three different incubation temperatures $\left(12^{\circ} \mathrm{C}, 16^{\circ} \mathrm{C}\right.$, and $20^{\circ} \mathrm{C}$ ). Prehatching embryos (at least 200 embryos from 


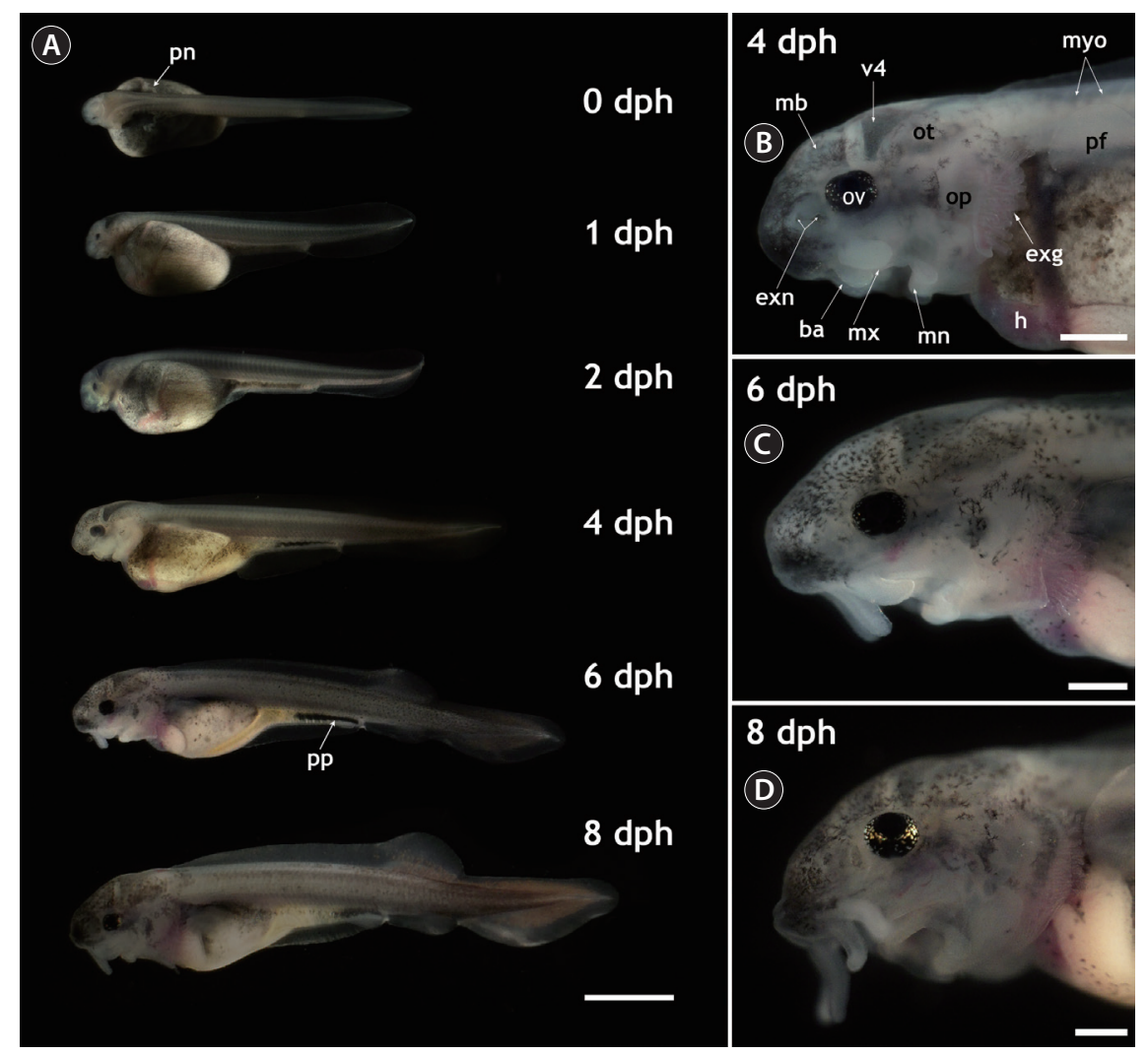

Fig. 1. (A-D) Morphological differentiations of Siberian sturgeon Acipenser baerii prolarvae from just hatching (0 days post hatching; $\mathrm{dph})$ to $8 \mathrm{dph}$. Magnified views of head region at selected ages are shown at right side. pn, pronephros; pp, pigment plug; mb, midbrain; v4, fourth ventricle; myo, myotomes; ov, optic vesicle; ot, otocyte; op, operculum; pf, pectoral fin; exg, external gills; exn, external nares; ba, barbels; mn, mandibular process; mx, maxillary process; $h$, heart. Scale bars: $A=3 \mathrm{~mm}, \mathrm{~B}-\mathrm{D}=0.5 \mathrm{~mm}$.

each group) that had developed under normal conditions at each temperature until the tail-beating stage were assigned to one of three new incubators (adjusted again to $12^{\circ} \mathrm{C}, 16^{\circ} \mathrm{C}$, or $20^{\circ} \mathrm{C}$ ). Afterward, hatched prolarvae were scored within a 24-h interval until hatching was complete. The completion of hatching in each group was defined as the absence of continued hatching over a period of $48 \mathrm{~h}$. Two replicates were used for each temperature group. Third, temporal patterns in the evacuation of the pigment plug in prolarvae were examined under three temperature conditions $\left(12^{\circ} \mathrm{C}, 16^{\circ} \mathrm{C}\right.$, and $\left.20^{\circ} \mathrm{C}\right)$ to evaluate the effects of incubation temperature on the transition of prolarvae to the external feeding stage. Immediately after hatching, prolarvae were collected from each temperature group and transferred to one of three new tanks that were also adjusted to $12^{\circ} \mathrm{C}, 16^{\circ} \mathrm{C}$, or $20^{\circ} \mathrm{C}$. The percentage of larvae that evacuated their pigment plugs was determined daily using a random sample of 36 individuals from each group. Accumulated mortality was also monitored daily and the survival rate from just after hatching until the completion of evacuation was compared among the three temperature groups. Two replicate groups were created for each temperature group.

\section{Statistics}

Statistical evaluations for the differences in developmental progress, hatchability, viability and rate of pigment plug evacuation were carried out using ANOVA followed by Duncan's multiple ranged tests using the SAS version 10. 3 (SAS Inc., Cary, NC, USA). Differences were considered to be significant when $P<0.05$.

\section{Results}

\section{Morphological appearance during ontogenic development in prolarvae}

The gross morphology of yolk-bearing prolarvae from hatching to $8 \mathrm{dph}$ is provided in Fig. 1. On the day of hatching (within $12 \mathrm{~h}$ after hatching), larvae had a large, yellow yolk sac and a straight shape. Pairs of distinct veins were visible on the surface of the yolk and the pigment plug was evenly spread inside the digestive tract. Pronephros ducts were still visible. Muscle segments could be clearly visible and each one 
could be distinguished from the others. Very little pigmentation in the embryonic body was observed in most prolarvae. At $1 \mathrm{dph}$ (36-40 $\mathrm{h}$ after hatching), the eye pigmentation was more pronounced and the fourth ventricle (i.e., one of the four connected cavities in the brain) appeared dark. Until $2 \mathrm{dph}$, growth in length was not significant and average length was $11 \pm 1.5 \mathrm{~mm}$; however, the yolk was slightly absorbed and the head structure became more evident. Rudimentary barbels were visible on the prolarvae. After $2 \mathrm{dph}$, the prolarvae started to undergo noticeable morphological transformations. Prolarvae at $4 \mathrm{dph}$ (total length [TL], $14 \pm 2.4 \mathrm{~mm}$ ) displayed significant pigmentation in the head region and on the abdominal cavity. The yolk sac was bipartite, with a furrow that formed the anterior stomach rudiment and the posterior midintestine. The pigment plug became concentrated and moved to the posterior part of the digestive tract. Pectoral fins budded on the yolk sac and were clearly visible. In the cephalic region, prolarvae at $4 \mathrm{dph}$ showed extended external gills that were generally not covered by the operculi. Fully pigmented optic vesicles and well-developed eye lenses were apparent. External nares with two connected holes were visible and the barbels were elongated, allowing the clear identification of each barbel. In addition, the midbrain, the fourth ventricle, and the otocysts could be distinguished in the lateral view. At $6 \mathrm{dph}$ (TL, $18 \pm 3.1 \mathrm{~mm}$ ), the prolarvae had more pigmentation over almost their entire bodies, especially in the cranial and caudal sections. The posterior margin of the yolk sac had been markedly reduced, the yolk sac had separated into presumptive organs, and organs in the abdominal cavity could be visualized. The dorsal fin was separated from the fin fold and rudimentary fin rays extended from the fin base. The anal and pelvic fins also began to appear as ridges in the fin fold. Meanwhile, the median fin anlage was evident in the caudal part with pigmentation. These prolarvae had more elongated barbels and distinctly developed operculi in the cephalic region. However, the external gills were still obvious during this stage. When the larvae reached $8 \mathrm{dph}$ (TL, $20 \pm 2.7 \mathrm{~mm}$ ), the yolk sac was difficult to discern clearly. Fin folds were more developed, the dorsal fin base was clearly visible and the anal and pelvic fins were evident. The heterocercal structure of the caudal fin was clear. The pigment plug had moved further in the anal direction and eventually started to be evacuated, indicating that the larvae were transitioning to exogenous feeding. Evacuation was first observed from $8 \mathrm{dph}$ and continued until $10 \mathrm{dph}$. In the lateral head view, the forth ventricle at $8 \mathrm{dph}$ was less contrasted than in earlier larvae due to the thickened cranial cover, which had significant pigmentation on its surface. Barbels were much more elongated. Although the external gills that had been prominent in earlier larval stages were largely covered by the extended operculi, the coverage was not yet complete. The gills were completely covered by the operculi at $20 \mathrm{dph}$.

\section{Larval development after yolk sac absorption}

After the transition to exogenous feeding (i.e., after the evacuation of the yolk plug), the larvae showed marked changes in both body weight and length. However, morphological modifications were less pronounced during the larval period than during the prelarval stage. At 2 weeks of age (14 dph), the larvae clearly had rudimentary scutes in the dorsal fin fold. Scute formation became more pronounced with age, such that fry at $20 \mathrm{dph}$ (TL, $35 \pm 3.7 \mathrm{~mm}$ ) had almost the full comple-

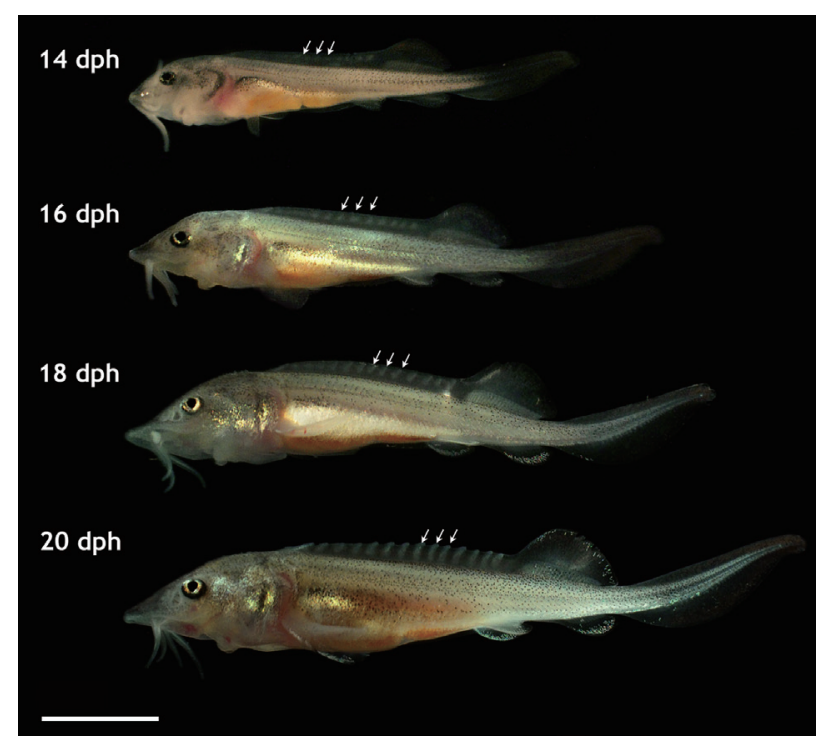

Fig. 2. Development of dorsal scutes Siberian sturgeon Acipenser baerii larvae during the phase of exogenous feeding (14 days post hatching [dph] to $20 \mathrm{dph}$ ). The 5 th to 7 th scutes from the dorsal fin were indicated by arrows. Scale bar $=5 \mathrm{~mm}$.

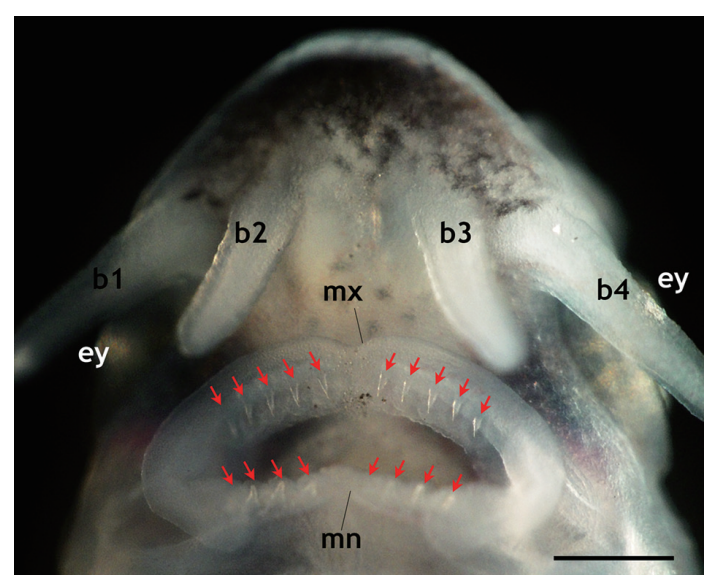

Fig. 3. Representative photograph to show the developed teeth in maxillary ( $\mathrm{mx}$; five pair of teeth) and mandibular ( $\mathrm{mn}$; four pair) of the Siberian sturgeon Acipenser baerii larvae at 9 days post hatching. Each tooth is indicated by arrow. Two pair of barbels (b1-b4) and eyes (ey) are also indicated. For temporal patterns of development, see Appendix 1. Scale bar $=5 \mathrm{~mm}$. 

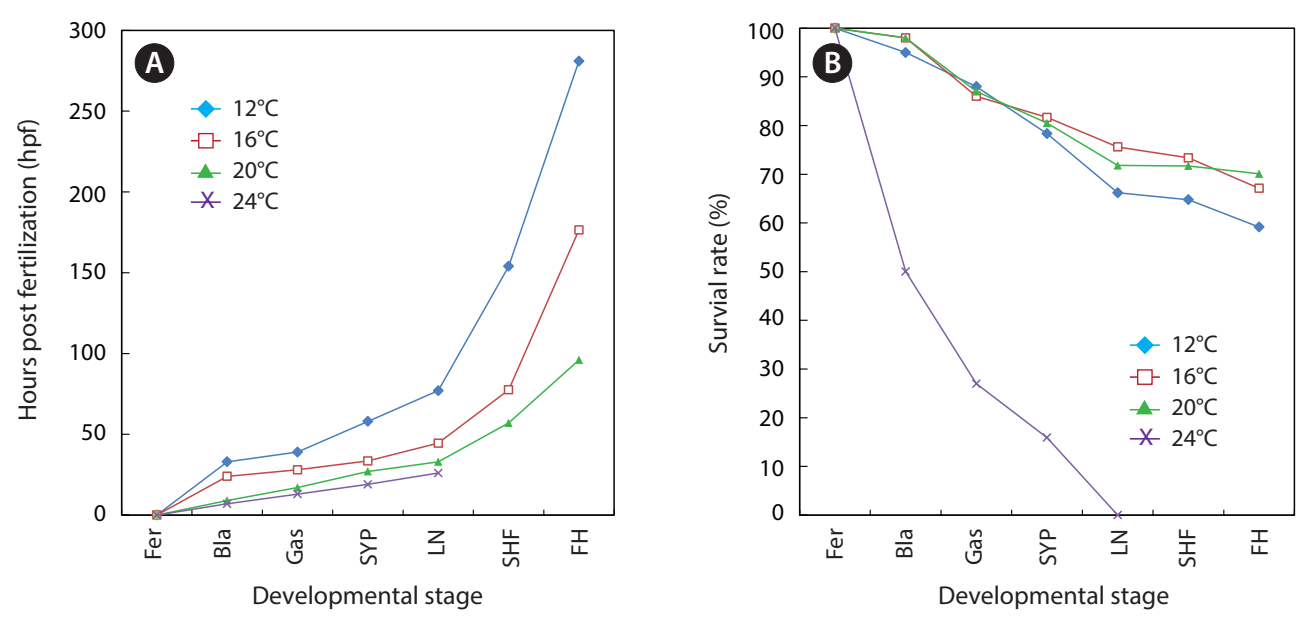

Fig. 4. Developmental progress (A) and survival rates (B) of Siberian sturgeon Acipenser baerii embryos incubated at different temperatures. Fer, fertilization; Bla, blastulation; Gas, gastrulation; SYP, small yolk plug formation; LN, late neurulation; SHF, S-heart formation; FH, first occurrence of hatching. Description for each developmental stage can be referred to Park et al. (2013). T-bars for standard deviations are omitted for better visibility.

ment that is seen in adult fish, including five arrays of scutes, a heterocercal caudal peduncle, and highly elongated barbels (Fig. 2). During development, the larvae exhibited transient occurrences of teeth. Tooth rudiments were first seen at $5 \mathrm{dph}$ in both the upper (maxillary) and lower (mandibular) layers (Appendix 1). The teeth lengthened and sharpened with age, and a shark tooth-like shape peaked at 9 and 11 dph (Fig. 3). Upper teeth were sharper and more tapered than lower teeth. However, the numbers of both upper and lower teeth were not uniform among individuals, with the number of upper teeth in most individuals ranging from 8 to 10 and the number of lower teeth ranging from 6 to 8 . Afterward, these teeth began to degenerate. The upper teeth became thinner while the lower teeth took on a blunted shape; both upper and lower teeth became shorter. During 15-17 dph, the teeth were less than half the size of those observed at 9-11 dph. At $19 \mathrm{dph}$, the teeth were only vestigial and they had disappeared completely by $21 \mathrm{dph}$ (Appendix 1).

\section{Embryonic development and yolk sac absorption under different temperature conditions}

As expected, developmental speed was significantly and negatively affected by incubation temperature, and the difference in developmental speed was more significant in later developmental phases (Fig. 4A). As a result, the time to reach the point of small yolk plug formation ranged from $19 \mathrm{~h}$ (at $24^{\circ} \mathrm{C}$ ) to $58 \mathrm{~h}$ (at $\left.12^{\circ} \mathrm{C}\right)$. Percent viability $(78-81 \%$ in average) at this stage did not differ significantly among the groups that were incubated at $12^{\circ} \mathrm{C}, 16^{\circ} \mathrm{C}$, or $20^{\circ} \mathrm{C}$. However, the embryos that were incubated at $24^{\circ} \mathrm{C}$ showed very low survival (16\%), and none of the embryos survived until the completion of neurulation. Only a few abnormal embryos reached neurulation, but all of them died (Fig. 4B). The time to reach the end of neu- rulation ranged from $33 \mathrm{~h}\left(20^{\circ} \mathrm{C}\right)$ to $77 \mathrm{~h}\left(12^{\circ} \mathrm{C}\right)$, and s-heart formation was observed at $57 \mathrm{~h}\left(20^{\circ} \mathrm{C}\right), 77.5 \mathrm{~h}\left(16^{\circ} \mathrm{C}\right)$, and $154 \mathrm{~h}\left(12^{\circ} \mathrm{C}\right)$. The first occurrence of hatching in the group incubated at $12^{\circ} \mathrm{C}$ was observed at $281 \mathrm{~h}$, while hatching first occurred at $176.5 \mathrm{~h}$ and $96 \mathrm{~h}$ in those incubated at $16^{\circ} \mathrm{C}$ and $20^{\circ} \mathrm{C}$, respectively. The percent survival in each of the temperature groups until the first occurrence of hatching was 59 $\pm 3.8 \%\left(12^{\circ} \mathrm{C}\right), 67 \pm 4.0 \%\left(16^{\circ} \mathrm{C}\right)$, and $70 \pm 1.8 \%\left(20^{\circ} \mathrm{C}\right)$. The survival rate was significantly lower at $12^{\circ} \mathrm{C}$ than at the other temperatures $(P<0.05)$.

The period from the first occurrence to the completion of hatching was also affected by incubation temperature (Fig. 5). At $12^{\circ} \mathrm{C}$, hatching was completed on Day 9 from the initial incubation of tail-beating embryos (i.e., Day 0), with more than $50 \%$ of the hatchings being recorded between Day 3 and Day 5. However, a considerable portion of the embryos showed delayed hatching, in which the hatching event continued until Day 9 (14\% of total hatchings). The overall hatching success for the initial embryos was only $56 \pm 4.5 \%$ and the percentage of abnormalities was $12 \pm 2.1 \%$. On the other hand, most of the hatching events in the $16^{\circ} \mathrm{C}$ treatment were completed within 5 days after incubation, except for a few abnormal embryos that hatched on Day 6 or Day 7 (less than 1\%). Mass hatching was observed on Day $3(31 \%)$ and Day $4(47 \%)$ at $16^{\circ} \mathrm{C}$. The hatching success was $78 \pm 6.1 \%$ and the incidence of abnormal hatchlings was $9 \pm 1.0 \%$. Meanwhile, for the embryos that were incubated at $20^{\circ} \mathrm{C}$, hatching only occurred over 3 days, barring exceptional abnormal embryos (less than $0.5 \%$ ) that hatched on Day 4 or Day 5 . After $4 \%$ of the embryos hatched on Day 1, nearly all of the remaining embryos hatched on Day 2 and Day 3. On average, $95 \pm 2.7 \%$ of the embryos successfully hatched, significantly more than at the two lower temperatures $(P<0.05)$. However, the percent incidence of abnormal larvae $(11 \pm 3.2 \%)$ at $20^{\circ} \mathrm{C}$ was similar to 

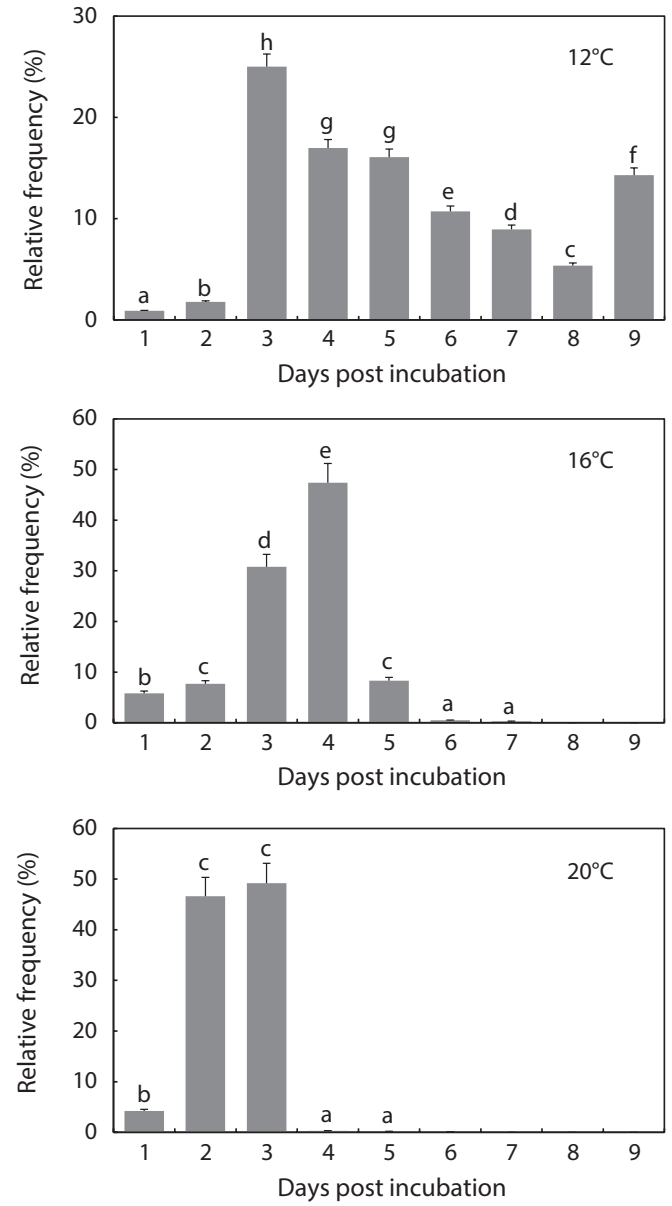

Fig. 5. Temporal patterns of the hatching event in Siberian sturgeon Acipenser baerii embryos incubated at three different temperatures. Prehatching (i.e., tail-beating and capable of moving) embryos that had been developed under each temperature condition was allocated again to tanks adjusted at one of the three temperatures and hatched prolarvae were counted in a daily basis. Means with different letters are significantly different based on ANOVA followed by Duncan's multiple ranged tests at $P<0.05$.

what was observed in the other temperature groups $(P>0.05)$.

The gross pattern of morphological differentiation in yolkbearing prolarvae, as characterized above, did not differ significantly among the temperature treatments, although temporal progress was inversely related with incubation temperature. Time to yolk sac absorption in prolarvae was significantly affected by incubation temperature (Fig. 6). At $12^{\circ} \mathrm{C}$, evacuation of the pigment plug was first observed at $14 \mathrm{dph}$ and it continued until $21 \mathrm{dph}$. On the other hand, pigment plugs began to be evacuated at $10 \mathrm{dph}$ and $6 \mathrm{dph}$, and was completed at $15 \mathrm{dph}$ and $8 \mathrm{dph}$, in the $16^{\circ} \mathrm{C}$ and $20^{\circ} \mathrm{C}$ treatments, respectively. The average survival rate from hatching to complete evacuation of the pigment plug was significantly lower at $12^{\circ} \mathrm{C}(68 \pm 5.8 \%)$ than at the other temperatures $\left(81 \pm 9.1 \%\right.$ at $16^{\circ} \mathrm{C}$ and $84 \pm$ $6.0 \%$ at $\left.20^{\circ} \mathrm{C}\right)(P<0.05)$.
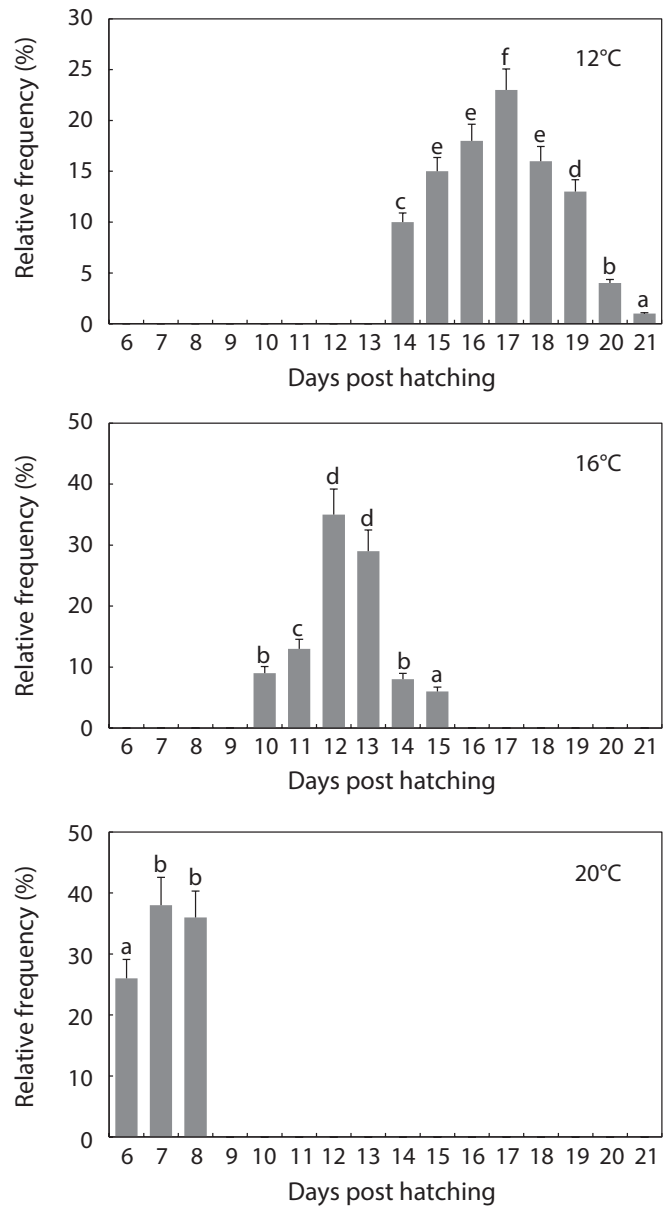

Fig. 6. Effects of incubation temperatures on the evacuation of pigment plug in Siberian sturgeon Acipenser baerii prolarvae. Means with different letters are significantly different based on ANOVA followed by Duncan's multiple ranged tests at $P<0.05$.

\section{Discussion}

Early ontogenic development in Siberian sturgeon prolarvae and larvae was documented, and the effects of temperature on early development were examined. Overall, the spatial and temporal patterns of larval morphogenesis documented in this study were congruent with other Acipenser species as well as with published descriptions of allometric development and growth patterns in this sturgeon species (Gisbert, 1999). Our observations (at $18^{\circ} \mathrm{C}$ ) are fairly consistent with those (at $17.8^{\circ} \mathrm{C}$ ) of a previous study on this species (Gisbert, 1999; Gisbert et al., 1999) regarding several morphological and/or behavioral aspects including yolk sac depletion, growth in total length, finfold development, and the formation of the heterocercal caudal fin. Furthermore, the photographic data, 
provided for the first time in the present study, clarified and confirmed the previous descriptions. However, the complete covering of the external gills by the operculi ( $9 \mathrm{dph}$ in the previous description vs. $20 \mathrm{dph}$ in the present study) and the formation of rudimentary dorsal scutes ( 9 dph vs. 13-14 dph) represented notable differences between the previous and present observations. The covering of the gill filaments by the operculi is known to be concomitant with the transition from cutaneous respiration to gill gas exchange (Dettlaff et al., 1993). Although we have not yet clarified the reason for this remarkable difference in the timing of gill covering, one possible but untested possibility is that the difference is related to different dissolved oxygen levels (former study $8.5 \mathrm{ppm}$ vs. present study $6.3 \mathrm{ppm}$ ) between the two studies. Higher oxygen levels might have accelerated the transition to brachial respiration in the previous study. Hence, observations of the progressive process of gill covering under different oxygen levels are needed to test this hypothesis. On the other hand, the difference in the onset of scute rudiment formation might have resulted from differences in water quality and/or dietary supply (probably with respect to the availability of minerals) between the two studies, because it is broadly agreed that minerals are important requirements for scute development in sturgeons (Khajepour and Hosseini, 2010). However, again, this hypothesis should be challenged with empirical observations. Meanwhile, the present study provided new details about the transient development of teeth during ontogenic development in Siberian sturgeon larvae. To date, temporal patterns in tooth development during larval stages in sturgeons have not been comprehensively studied. In this study, temporal changes in tooth development, as well as morphological features, were newly characterized. Siberian sturgeon prolarvae developed tooth rudiments as early as $5 \mathrm{dph}$ and the development of shark-like teeth peaked during the period from 9 to $11 \mathrm{dph}$; afterward, the teeth degenerated progressively and completely disappeared by $21 \mathrm{dph}$. Individual variation was found in the numbers of teeth in both the maxillary and mandibular layers. Although the mechanism or biochemical signaling that is responsible for the development and degeneration of transient teeth in sturgeons is not yet understood, it is thought that the teeth are associated with the seizing and fragmentation of exogenous food (e.g., probably benthic invertebrates) (Gisbert, 1999; Ostos-Garrido et al., 2009; Kirschbaum and Williot, 2011). In the present study, the peak in tooth development between 9 and $11 \mathrm{dph}$ was congruent with the commencement of exogenous feeding, which occurred immediately after the evacuation of the yolk plug. A previous study reported that complete differentiation of the cardiac stomach and increased activities of related digestive enzymes in Siberian sturgeon larvae should occur during this period (Gisbert et al., 1999), and this coincided with tooth development in this study. However, the relationship between tooth degeneration and changes in behavior and/or digestive functions needs to be explored further.
In the temperature experiments, fertilized Siberian sturgeon embryos developed normally at three of the experimental temperatures $\left(12^{\circ} \mathrm{C}, 16^{\circ} \mathrm{C}\right.$, and $\left.20^{\circ} \mathrm{C}\right)$, but embryos incubated at $24^{\circ} \mathrm{C}$ failed to development from the gastrulation stage. Bearing in mind that at least a portion of the embryos that were incubated at $24^{\circ} \mathrm{C}$ showed successful development during the early cleavage phase, the heat-mediated problem would manifest during the formation of germ layers (i.e., gastrulation) and/or organogenesis (i.e., neurulation). These stages are known to be essentially responsible for the initial programming of asymmetry and body structure in fish (Bolker, 2004; Cooper and Virta, 2007). None of the embryos at $24^{\circ} \mathrm{C}$ showed formation of the pronephros and heart rudiments, the two typical indicators of successful completion of neurulation in sturgeons (Dettlaff et al., 1993; Park et al., 2013). The lethality at $24^{\circ} \mathrm{C}$ observed in this study is similar to a previous finding on another sturgeon species, Acipenser gueldenstaedtii (Wang et al., 1985). Like most embryos of poikilothermic animals, the rate of development in Siberian sturgeon was inversely correlated with incubation temperature. The time until the first occurrence of hatching at $20^{\circ} \mathrm{C}(96 \mathrm{hpf})$ was less than $35 \%$ of the time that was required at $12^{\circ} \mathrm{C}$ and approximately half of the time at $16^{\circ} \mathrm{C}$. However, there was no significant difference in the size (total length) of hatched prolarvae among the temperature groups (data not shown).

More importantly, the incubation of Siberian sturgeon embryos at temperatures close to $20^{\circ} \mathrm{C}$ could provide advantages over low-temperature incubation, because there was a much more synchronized timing window for hatching events. At $20^{\circ} \mathrm{C}$, the hatching events of almost all of the tail-beating embryos were completed within only 3 days. Lower incubation temperatures resulted in significantly lagged periods: at least 5 and 9 days at $16^{\circ} \mathrm{C}$ and $12^{\circ} \mathrm{C}$, respectively. Furthermore, hatchability was significantly higher at $20^{\circ} \mathrm{C}$ than at the two lower temperatures, without any notable signs of additional abnormalities. This synchronized pattern at $20^{\circ} \mathrm{C}$ has important implications for hatchery practices; it could help managers make more accurate decisions about the timing of initial feeding. Under hatchery conditions, large variation in the timing of hatching inevitably leads to non-uniform larval populations, which consequently results in the unavoidable and unwanted loss of a portion of the larvae that show either advanced or delayed development. It is widely agreed that an earlier supply of artificial food, before the complete transition to exogenous feeding, would not provide any advantage to larvae, while a late food supply would significantly depress both growth and viability (Gisbert and Williot, 1997). Moreover, a considerable portion of the embryos that were incubated at the lower temperatures (particularly at $12^{\circ} \mathrm{C}$ ) did not hatch and eventually died, although they appeared to be morphologically healthy. Dead embryos would cause bacterial and fungal propagation, followed by frequent infections in living embryos during large-scale production.

After hatching, the development of yolk-bearing prolar- 
vae, up to the evacuation of the pigment plug, was also significantly stimulated under the higher incubation temperature $\left(20^{\circ} \mathrm{C}\right.$ in this study). The timing window for the evacuation of the pigment plug was also narrower in the $20^{\circ} \mathrm{C}$ treatment than in the other treatments. Transition to exogenous feeding in sturgeon larvae is highly correlated with the ejection of the pigment plug after yolk sac depletion. Larval viability and development are sensitive to the availability of exogenous food, which needs to be provided in a timely manner after the expulsion of the pigment plug (Conte et al., 1988; Gisbert and Ruban, 2003). For this reason, the uniformity in the transition from yolk sac nutrition to exogenous feeding would be beneficial for larval rearing in sturgeon hatcheries. Taken together, the results of this study strongly suggest that an incubation temperature close to $20^{\circ} \mathrm{C}$ is beneficial for both embryonic development and prelarval incubation in Siberian sturgeon, as evidenced by the shortened period and synchronized pattern. Further studies are needed to validate the present results and to determine if they can be replicated under various hatchery conditions. If such future studies are successful, the data from this study will provide a useful technical guideline for hatchery practices and the management of Siberian sturgeon.

\section{Acknowledgements}

This study was supported by a research fund from the Ministry of Land, Transport and Maritime Affairs, Korea (project \#20088033-1). Authors express sincere thanks to Mr. Won Sun Yoon (Korea Sturgeon Aquafarm Inc.) for his kind providing the fertilized eggs for this study.

\section{References}

Akbarzadeh A, Farahmand H, Mahjoubi F, Nematollahi MA, Leskinen P, Rytkönen K and Nikinmaa M. 2011. The transcription of 1-gulono-gamma-lactone oxidase, a key enzyme for biosynthesis of ascorbate, during development of Persian sturgeon Acipenser persicus. Comp Biochem Physiol B Biochem Mol Biol 158, 282288. http://dx.doi.org/10.1016/j.cbpb.2010.12.005.

Billard R and Lecointre G. 2001. Biology and conservation of sturgeon and paddlefish. Rev Fish Biol Fish 10, 355-392. http://dx.doi. org/10.1023/A:1012231526151.

Birstein VJ, Hanner R and DeSalle R. 1997. Phylogeny of the Acipenseriformes: cytogenetic and molecular approaches. Environ Biol Fishes 48, 127-155. http://dx.doi.org/10.1023/A:1007366100353.

Bolker JA. 2004. Embryology. In: Sturgeons and Paddlefish of North America. LeBreton GTO, Beamish FWH and McKinley SR, eds. Kluwer Academic Publishers, Dordrecht, NL, pp. 134-146.

Cho YS, Douglas SE, Gallant JW, Kim KY, Kim DS and Nam YK. 2007. Isolation and characterization of cDNA sequences of Lgulono-gamma-lactone oxidase, a key enzyme for biosynthesis of ascorbic acid, from extant primitive fish groups. Comp Bio- chem Physiol B Biochem Mol Biol 147, 178-190. http://dx.doi. org/10.1016/j.cbpb.2007.01.001.

Conte FS, Doroshov SI, Lutes PB and Strange EM. 1988. Hatchery Manual for the White Sturgeon. Publication No. 3322. University of California Press, Oakland, CA, US, pp. 104.

Cooper MS and Virta VC. 2007. Evolution of gastrulation in the rayfinned (Actinopterygian) fishes. J Exp Zool B Mol Dev Evol 308, 591-608. http://dx.doi.org/10.1002/jez.b.21142.

Dettlaff TA, Ginsburg AS and Schmalhausen OI. 1993. Sturgeon Fishes: Developmental Biology and Aquaculture. Springer-Verlag, New York, US.

Gisbert E. 1999. Early development and allometric growth patterns in Siberian sturgeon and their ecological significance. J Fish Biol 54, 852-862. http://dx.doi.org/10.1111/j.1095-8649.1999.tb02037.x.

Gisbert E and Ruban GI. 2003. Ontogenic behavior of Siberian sturgeon, Acipenser baerii: a synthesis between laboratory tests and field data. Envrion Biol Fishes 67, 311-319. http://dx.doi. org/10.1023/A:1025851502232.

Gisbert E and Williot P. 1997. Larval behaviour and effect of the timing of initial feeding on growth and survival of Siberian sturgeon (Acipenser baeri) larvae under small scale hatchery production. Aquaculture 156, 63-76. http://dx.doi.org/10.1016/S00448486(97)00086-0.

Gisbert E and Williot P. 2002. Advances in the larval rearing of Siberian sturgeon. J Fish Biol 60, 1071-1092. http://dx.doi.org/10.1111/ j.1095-8649.2002.tb01705.x.

Gisbert E, Sarasquete MC, Williot P and Castelló-Orvay F. 1999. Histochemistry of the development of the digestive system of Siberian sturgeon during early ontogeny. J Fish Biol 55, 596-616. http:// dx.doi.org/10.1111/j.1095-8649.1999.tb00702.x.

Gisbert E, Williot P and Castelló-Orvay F. 2000. Influence of egg size on growth and survival of early stages of Siberian sturgeon (Acipenser baeri) under small scale hatchery conditions. Aquaculture 183, 8394. http://dx.doi.org/10.1016/S0044-8486(99)00287-2.

Khajepour F and Hosseini SA. 2010. Mineral status of juvenile beluga (Huso huso) fed citric acid supplemented diets. World Appl Sci J $11,682-686$.

Kim DS, Nam YK, Noh JK, Park CH and Chapman FA. 2005. Karyotype of North American shortnose sturgeon Acipenser brevirostrum with the highest chromosome number in the Acipenseriformes. Ichthyol Res 52, 94-97. http://dx.doi.org/10.1007/s10228-0040257-z.

Kim KY, Lee SY, Song HY, Park CH and Nam YK. 2009. Complete mitogenome of the Russian sturgeon Acipenser gueldenstaedtii (Acipenseriformes; Acipenseridae). J Fish Sci Technol 12, 35-43. http://dx.doi.org/10.5657/fas.2009.12.1.035.

Kirschbaum F and Williot P. 2011. Ontogeny of the European sturgeon, Acipenser sturio. In: Biology and Conservation of the European Sturgeon Acipenser sturio L. 1758. Williot P, Rochard E, DesseBerset N, Kirschbaum F and Gessner J, eds. Springer, Berlin and Heidelberg, DE, pp. 65-80. http://dx.doi.org/10.1007/978-3-64220611-5_5.

Ostos-Carrido MV, Llorente JI, Camacho S, García-Gallergo M, Sanz A, Domezain Z and Carmona R. 2009. Histological, histochemi- 
Park et al. (2013) Temperature-dependent Development of Siberian Sturgeon Egg and Prolarvae

cal and ultrastructural changes in the digestive tract of sturgeon Acipenser naccarii during early ontogeny. In: Biology, Conservation and Sustainable Development of Sturgeons. Carmona R, Domezain A, García Gallego M, Hernado JA, Rodríguez F and RuizRejón M, eds. Springer, Dordrecht, NL, pp. 121-136. http://dx.doi. org/10.1007/978-1-4020-8437-9_7.

Park CH. 2012. Sexual maturation and vitellogenin expression of Siberian sturgeon Acipenser baerii farmed in Korea. MSc. Thesis, Pukyong National University, Busan, KR.

Park CH, Lee SY, Kim DS and Nam YK. 2013. Embryonic development of Siberian sturgeon Acipenser baerii under hatchery conditions: an image guide with embryological descriptions. Fish Aquat Sci $16,15-23$.

Seong KB and Baik KK. 1999. The early growth of Siberian sturgeon, Acipenser baeri in the internal transplantation. Bull Natl Fish Res Dev Inst Korea 57, 87-93.

Vasil'ev VP. 2009. Mechanisms of polyploid evolution in fish: poly- ploidy in sturgeons. In: Biology, Conservation and Sustainable Development of Sturgeons. Carmona R, Domezain A, García Gallego M, Hernado JA, Rodríguez F and Ruiz-Rejón M, eds. Springer, Dordrecht, NL, pp. 97-117. http://dx.doi.org/10.1007/978-1-40208437-9_6.

Wang YL, Binkowski FP and Doroshov SI. 1985. Effects of temperature on early development of white and lake sturgeon, Acipenser transmontanus and A. fulvescens. Environ Biol Fishes 14, 43-50. http:// dx.doi.org/10.1007/BF00001575.

Webb MAH and Doroshov SI. 2011. Importance of environmental endocrinology in fisheries management and aquaculture of sturgeons. Gen Comp Endocrinol 170, 313-321. http://dx.doi.org/10.1016/j. ygcen.2010.11.024.

Zeiske E, Kasumyan A, Bartsch P and Hansen A. 2003. Early development of the olfactory organ in sturgeons of the genus Acipenser: a comparative and electron microscopic study. Anat Embryol 206, 357-372. http://dx.doi.org/10.1007/s00429-003-0309-6. 


\section{Appendix 1.}

Transient development of teeth in prolarvae and larvae of Siberian sturgeon Acipenser baerii during 5 days post hatching (dph) to $21 \mathrm{dph}$ under the constant temperature condition $\left(18{ }^{\circ} \mathrm{C}\right)$. The teeth rudiments were firstly observable at $5 \mathrm{dph}$. Afterward, the development of teeth was peaked at 9 to $11 \mathrm{dph}$, and then began to degenerate. At $21 \mathrm{dph}$, teeth were completely diminished.

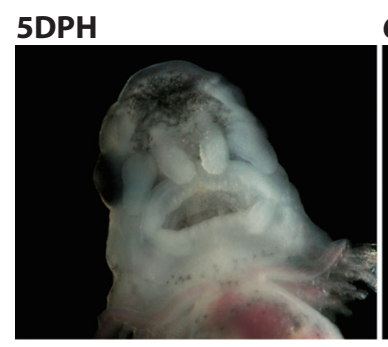

6DPH

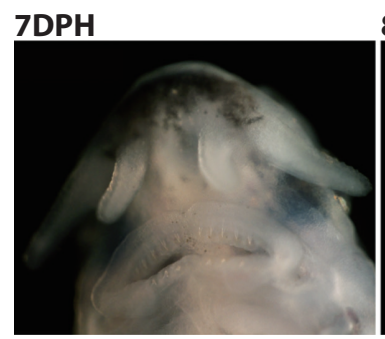

8DPH

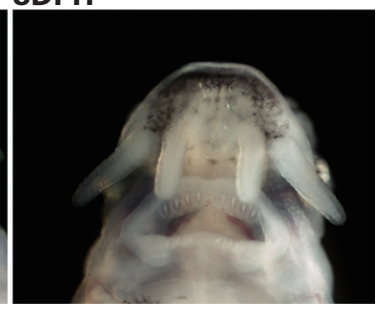

\section{DPH}

10DPH

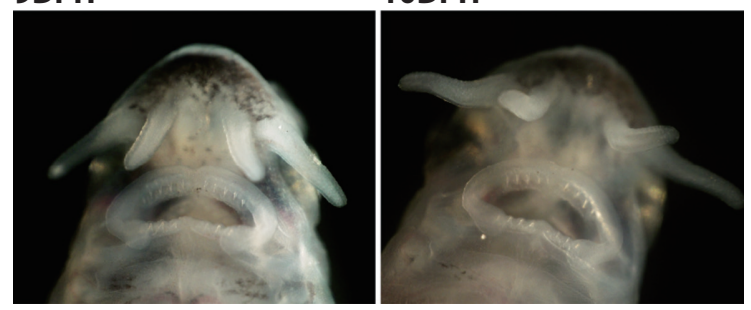

11DPH

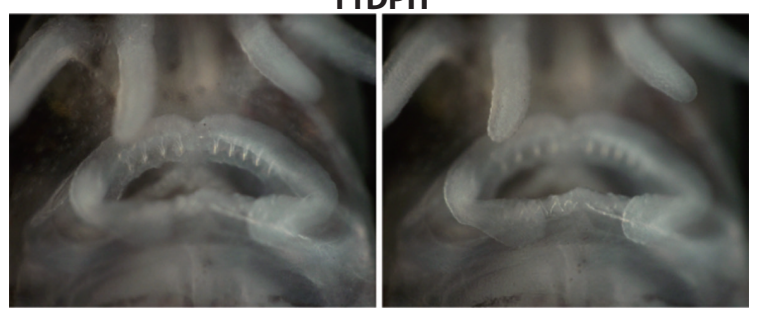

13DPH

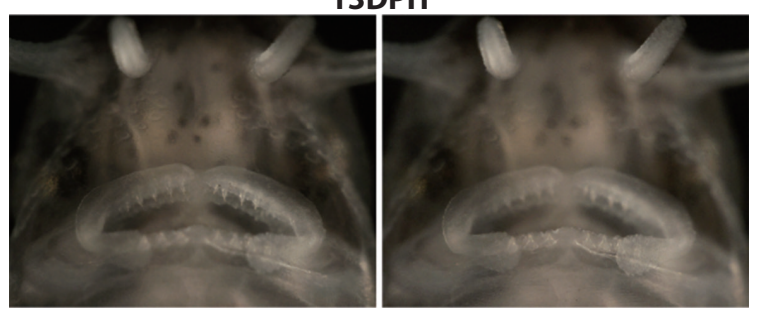

15DPH

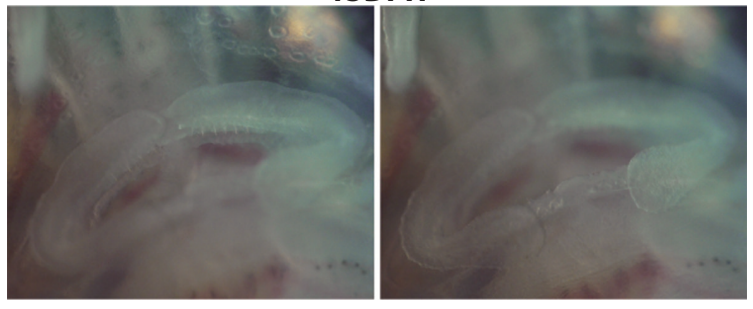

17DPH

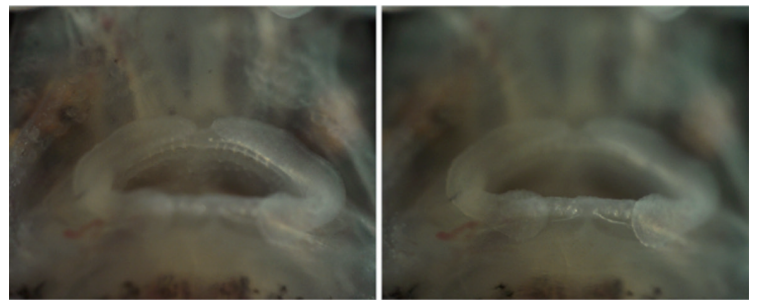

19DPH

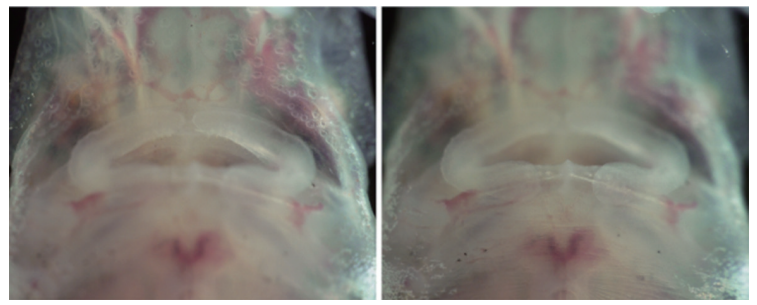

21DPH

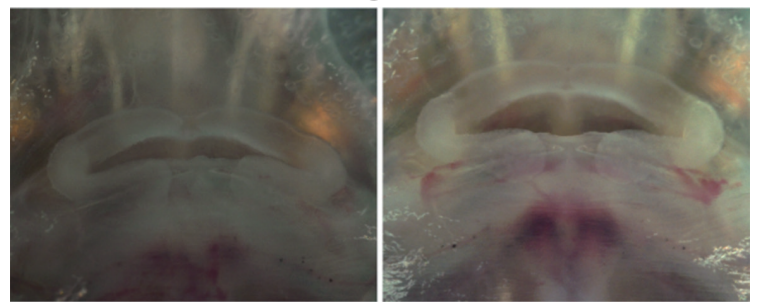

